\title{
OS VALORES ÉTICOS NA ORGANIZAÇÃO E REPRESENTAÇÃO DO CONHECIMENTO ARQUIVÍSTICO
}

\author{
Ethical Values in Archival knowledge Organization and Representation
}

\author{
Andrieli Pachú da Silva (1), Natália Bolfarini Tognoli, José Augusto Chaves Guimarães \\ (1) Universidade Estadual Paulista (UNESP), Faculdade de Filosofia e Ciências, Marília. Av. Hygino Muzzi Filho, 737, \\ 17525-900 - Marília - SP - Brasil, email: andrielipachu@ marilia.unesp.br; nataliatognoli@ marilia.unesp.br; \\ guima@marilia.unesp.br
}

\begin{abstract}
Resumo
As funções classificação e descrição configuram-se como processos nucleares no âmbito da organização e representação do conhecimento arquivística por representarem pontos de intersecção entre as demais ações relacionadas aos documentos de arquivo, revelando um universe axiológico rico e diversificado. Nesse sentido, aborda-se a ética arquivística no âmbito dessas duas funções a partir dos valores identificados e sistematizados por Silva (2016) em 16 códigos de ética da profissão. Por meio de uma análise de conteúdo, foram identificados onze valores: acesso à informação, respeito à proveniência, respeito à ordem original, preservação e conservação do documento, preservação do valor arquivístico do documento, confiabilidade, custódia, imparcialidade, autenticidade e segurança da informação. Apresenta-se, assim, uma reflexão sobre cada valor e como estão relacionados às funções de classificação e descrição, demonstrando a importância da discussão sobre a ética no contexto da Arquivística, notadamente no tocante à organização do conhecimento arquivístico que, nos últimos anos, vem ganhando significativo espaço no âmbito da International Society for Knowledge Organization - ISKO.
\end{abstract}

Keywords: Ética arquivística. Organização e Representação do Conhecimento. Valores éticos

\section{Introdução}

Os estudos sobre a ética no contexto da Arquivística brasileira configuram-se como um vasto campo a ser explorado, tanto pelos arquivistas, quanto por professores, alunos e pesquisadores da área. Essa discussão se faz necessária para compreender a atuação profissional do arquivista e quais os valores que o movem. Segundo Mason (1990) toda profissão está baseada em quatro pilares: seu conhecimento teórico, seus procedimentos e métodos, sua história e sua ética.

\begin{abstract}
Archival classification and archival description can be considered nuclear processes within archival knowledge organization and representation once they represent intersection points between the other actions related to records, revealing a rich and diverse axiological universe. In this sense we discuss the archival ethics linked to these two major functions from the values identified and systematized by Silva (2016) in sixteen codes of ethics of archivists. Eleven values were found through a content analysis: information access, respect of provenance, respect of original order, record preservation and conservation, preservation of archival value, realiability, custody, impartiality, autheticity and information security. We present a reflection about each value and how it is related to classification and description in archives, demonstrating the importance of the discussion on ethics in Achival Science, especially related to archival knowledge organization, which in recent years has been gaining prominence within the International Society for Knowledge Organization ISKO.
\end{abstract}

Keywords2: Archival ethics. Knowledge Organization and Representation. Ethical values

Ao observarmos a literatura da área, notamos que os valores modificam-se ao passar do tempo, como por exemplo: a compreensão do papel do arquivista, como um "guardião imparcial dos documentos", como propagava Sir Hilary Jenkinson, atuando exclusivamente com documentos históricos até meados do século XX (Cook, 1997).

Tal compreensão se modifica de acordo com a realidade e necessidade social; assim, as dificuldades enfrentadas por Schellenberg (na década de 1950) e seus co- 
legas de profissão nos Estados Unidos demandaram uma reformulação da atuação profissional do arquivista frente à explosão da produção documental - consequência do desenvolvimento tecnológico e científico, bem como aumento da burocracia no pós-guerra - e à necessidade do estabelecimento de uma política de avaliação documental. O arquivista passa, então, a atuar na gestão desses documentos, desde a sua produção até as políticas de acesso e uso. ${ }^{(1)}$

Terry Cook (1997), na introdução de sua análise sobre a história do pensamento arquivístico ao longo de um século, retoma que a mudança de postura do arquivista com relação à intervenção nos processos de produção e de recuperação do documento demonstraram sua capacidade de compreender a natureza do documento de arquivo, interpretando sua função, estrutura, processo administrativo e contexto documental, indo além do conteúdo histórico, alterando, assim, o valor de imparcialidade atribuído ao arquivista e aos documentos de arquivo, por exemplo.

Barros (2015) destaca que os estudos sobre a ética no âmbito da Arquivística fazem parte da reconfiguração e redefinição da disciplina a partir da década de 1980. Ainda segundo o autor "uma vez que o posicionamento teórico vem sendo revisto, o arquivista também precisa reavaliar o seu posicionamento e as suas responsabilidades" (2015, p. 19). Nesse sentido, o conhecimento do domínio teórico e prático deve estar ligado aos valores éticos propagados pelos profissionais, uma vez que tal profissão pressupõe uma expressão social e moral (Sá, 2000).

A questão social e moral a partir da perspectiva dos profissionais da informação, como demonstra o estudo de Souza (2002) sobre as questões éticas e deontológicas na área da Biblioteconomia, destaca que "compreender a ética das profissões da informação e sua deontologia exige uma competência específica das entidades formadoras de profissionais, o que coloca a universidade e as entidades profissionais diante de um compromisso com o próprio futuro da sociedade" (Souza, 2002, p. 16). Assim, as questões éticas devem ser pensadas juntamente com o aprendizado teórico de uma área e essa discussão deve ser estendida para além da formação do profissional.

Nesse sentido, o arquivista se coloca como um professional qualificado, entendido por Mason (1990) como aquele que, detentor de um conhecimento especializado, o utiliza a serviço da sociedade. Desse modo, e mais especificamente como um dos profissionais da informação (Mason, 1990), proporciona o apoio à "produção, seleção e conservação dos documentos, pois torna-os disponíveis para uso" (ICA, 2010). Buscamos, nesse artigo, discutir os valores que se apresentam aos arquivistas no âmbito das funções de classificação e descrição - consideradas nucleares na organização e representação do conhecimento arquivístico - a partir da análise e sistematização dos valores por Silva (2016) em 16 códigos de ética da profissão.

\section{2 Ética arquivística}

A palavra ética traz consigo uma diversidade conceitual a partir de diferentes concepções teóricas, mas tem como substrato ser inerente ao homem, em sua vida em sociedade (Abela, 2008).

A ética, como apresenta Sá (2000), pode ser entendida em seu sentido amplo como "a ciência da conduta humana perante o ser e seus semelhantes" (Sá, 2000, p. 15), reafirmando os dois elementos que lhe são intrínsecos: o homem e a sociedade.

Integrando o universo de estudos da Filosofia, a ética, “está mais preocupada em detectar os princípios de uma vida conforme a sabedoria filosófica, em elaborar uma reflexão sobre as razões de se desejar a justiça e a harmonia e sobre os meios de alcançá-las", diferente da moral que se preocupa com a "construção de um conjunto de prescrições destinadas a assegurar uma via em comum justa e harmoniosa", ou seja, a moral diz respeito "aos costumes, valores e normas de conduta específicos de uma sociedade ou cultura", enquanto a ética "considera a ação humana do seu ponto de vista valorativo e normativo, em um sentido mais genérico e abstrato" (Japiassú; Marcondes, 2008, p. 97 e 193).

Cortina e Martinez (2005) destacam uma tripla função da ética, no sentido de esclarecer o que é moral, trazer fundamentos à moralidade, e, como resultado, aplicar, em um dado contexto social, os resultados advindos dessas duas funções (Cortina; Martinez, 2005, p. 21).

Destaca-se aqui a função aplicada, pois, é nos diferentes âmbitos da vida social que se pode encontrar a dimensão da ética relacionada às profissões, entendida por Guimarães (2006) como "um conjunto de valores que um dado segmento social, caracterizado pela especificidade de um saber e de um fazer (profissão), estabelece como necessários e fundamentais ao exercício dessa profissão, decorrendo de questões de responsabilidade profissional" (Guimarães, 2006, p. 237).

No âmbito da Ciência da Informação, a ética vem sendo discutida sob alguns aspectos como demonstra o estudo realizado por Bufrem et. al. (2008), ao analisar a produção científica da área na base de dados BRAPCI, referente ao período de 1970 a 2006, buscando as tendências investigativas sobre a temática ética.

O estudo identificou a presença de nove tendências, sendo elas: ética profissional, ética e conhecimento científico, ética e tecnologia, ética - aspectos teóricos, ética e direito à informação, ética nas organizações, ética e direito autoral, ética e trabalho, ética e políticas de informação. No entanto, a maioria dos artigos estão voltados "às questões específicas da formação profissional de bibliotecários, imbricada com preocupações 
contemporâneas do universo do trabalho" (Bufrem et. al. 2008, p. 229.).

Verticalizando a questão para as atividades de organização e representação do conhecimento na literatura da Ciência da Informação, Guimarães, Milani e Pinho (2008) dedicam especial atenção aos valores que, nesse contexto, refletem crenças e comportamentos que, em dado âmbito social, assumem a condição de princípios, normas ou padrões consensualmente eleitos em direta sincronia com as raízes culturais de cada sociedade. Tal aspecto dá origem à reflexão ética, ou julgamento moral (Guimarães, Milani, Pinho, 2008, p. 125).

Ainda no âmbito da Ciência da Informação, Guimarães e Fernandez-Molina (2010), ao realizarem um estudo sobre a literatura no que tange à organização e representação do conhecimento, identificam os valores relacionados a três esferas: a dos valores superiores que "devem guiar toda a atividade informativa", a dos valores "reconhecidos previamente como requisitos profissionais porque são essenciais para a ação profissional", e a dos valores que, embora por muito tempo tidos "como simples medidas de recuperação da informação" são "porém reconhecidos como parte do universo axiológico da organização e representação do conhecimento" (Guimarães; Fernandez-Molina, 2010, p.244 tradução livre). Essa discussão vem somar a outro estudo dos autores (Fernandez-Molina; Guimarães, 2002) em que os valores relacionados às atividades de organização e representação do conhecimento foram analisados a partir da realidade de 16 códigos de conduta dos profissionais bibliotecários, enfatizando a tônica obre as atividades de gestão e de atendimento ao usuário, com poucas referências aos valores envolvidos na organização da informação (Fernández-Molina; Guimarães, 2002, p. 491).

Trazendo esse entendimento de função aplicada da ética para o universo profissional dos arquivistas, surge a necessidade de melhor compreender a ética para tais profissionais que se deparam com situações que precisam ser resolvidas para que as atividades de organização e representação da informação possam ser realizadas de forma confiável.

Ao analisar alguns estudos sobre ética na área, observou-se que, em alguns deles, a tônica da discussão recai sobre o que se pode entender como ética e a formação profissional do arquivista, (Cox, 2010; Gilliland, 2011), outros referem-se aos códigos de ética (Dingwall, 2004; Cook, 2006; Wallace, 2010; Mitchell, 2013; Bellotto, 2014; Rego et. al., 2014, Silva, Guimarães, Tognoli, 2015), e também nos relatos de dilemas éticos que o profissional e/ou as instituições arquivísticas enfrentam (Eriksen, 2010; Cox, 2013; Danielson, 2013). No entanto, é válido ressaltar que todos esses estudos perpassam aquilo a que Danielson (2010) se refere como as diversas formas de visualizar a ética arquivística, retomando sempre a perspectiva legal, as normas estabelecidas pela própria categoria profissional e a responsabilidade social.

Ao discorrer sobre a necessidade do estudo da ética na formação do arquivista, Cox (2010) relata sua experiência como professor da disciplina Archival Acess, Advocacy, and Ethics, e salienta sobre a necessidade de trabalhar questões éticas juntamente com o aprendizado teórico da área, pois "inserir alguém nos meandros das normas descritivas e de metadados é uma coisa, mas não se pode esperar muito se esse indivíduo não está preparado para lidar com as questões de propriedade intelectual, privacidade, questões legais, e uma série de outras questões com implicações éticas" (Cox, 2010, p. 28 , tradução livre).

$\mathrm{O}$ autor ainda recorda que os arquivistas trabalham em um local voltado não apenas para preservar a memória social ou coletiva, mas também para revelar o que fora obscuro em uma determinada época. Assim "a aquisição, conservação, representação, e acesso dos materiais de arquivo sempre têm o potencial de envolver os arquivistas em disputas e desastres, não importando o quão cuidadosos ou conservadores sejam os esforços [desses profissionais]" (Cox, 2010, p. 26, tradução livre).

Gilliland (2011) destaca a importância da discussão ética no ensino e na formação desses arquivistas, pois o conteúdo dos códigos de ética profissional tende a não englobar as atividades dos professores nos cursos de graduação ou pós-graduação em Arquivologia, uma vez que esses códigos são dirigidos às preocupações relacionadas à prática profissional e não ao ensino acadêmico. Assim, esses professores preparam os futuros profissionais para a prática do arquivo, bem como os pós-graduandos no ensino e na pesquisa. O papel de ensinar exige que esses professores se mantenham atualizados com a prática profissional, bem como compreender e comunicar os valores e as preocupações que estão envoltos na atuação profissional (Gilliland, 2011, p.199, tradução livre).

Um exemplo significativo sobre essa questão é compartilhado pela autora ao relatar sobre o programa de pós-graduação do departamento de Information Studies da University of California, Los Angeles em que a disciplina Ethics, Diveristy and Change é requerida a todos os alunos de mestrado (Gilliland, 2011).

Se a questão ética perpassa todo o fazer profissional do arquivista tem-se, como consequência, sua influência direta nos processos nucleares da área, ligados à organização do conhecimento arquivístico.

\section{Organização e Representação do Conhecimento Arquivístico}

Consideramos neste estudo, a Arquivística como uma dimensão teórica e profissional que pode ser discutida no âmbito da Ciência da Informação, sendo um campo 
que ampara as teorias e práticas ligadas aos processos e fluxos da informação "[...] desde sua criação até a sua utilização, e sua transmissão ao receptor em uma variedade de formas, por meio de uma variedade de canais" (Smit; Barreto, 2002, p. 17-18). Reitera-se, assim, o seu papel de "[...] fornecer um conjunto de informações que levam melhorias às diversas instituições e procedimentos dedicados à acumulação e transmissão de conhecimentos" (Borko, 1968, p. 2, tradução livre) que foram registradas para que perdurassem ao longo do tempo e fossem localizadas no espaço, de modo a gerar conhecimento individual e social. Essas informações registradas são "[...] estocadas em função de um uso futuro, causando a institucionalização da informação" (Smit; Barreto, 2002, p. 21-22).

No caso, tem-se um conjunto de princípios e práticas desenvolvidos no arquivo relativos às funções arquivísticas necessárias à gestão completa dos documentos produzidos por uma instituição e definidas por Couture (2000) como: (1) Análise das necessidades; (2) Produção; (3) Avaliação; (4) Aquisição; (5) Classificação; (6) Descrição e indexação; (7) Difusão e; (8) Preservação.

Os documentos de arquivo constituem-se, portanto, em elemento fundamental à atuação arquivística, definidos como registros informacionais específicos, "[...] produtos de uma atividade de coleção consciente, vinculados ao processo pelos quais foram gerados" (Thomassem, 2006, p. 6).

Esse vínculo documental é mantido e percebido a partir da aplicação do princípio norteador da Arquivística, o respect des fonds, que segundo Duchein (1983, p. 64, tradução livre), "[...] significa agrupar, sem misturar a outros, os arquivos (documentos de qualquer tipo) criados por ou advindos de uma administração, estabelecimento, pessoa ou instituição".

Assim, todas as funções arquivísticas ou as atividades e intervenções realizadas e/ou desenvolvidas pelos arquivistas ocorrem, segundo Rousseau e Couture (1998, p. 79), à luz do princípio da proveniência, bem como o "[...] reconhecimento do fundo de arquivo como unidade central das operações arquivísticas".

De forma a estabelecer uma ponte entre a informação produzida e aquele que dela fará uso, torna-se necessário um conjunto de atividades, dentre as quais se destacam a classificação e a descrição arquivística, consideradas funções nucleares no processo da organização e representação do conhecimento arquivístico.

O termo conhecimento arquivístico foi originalmente cunhado por Tognoli, Guimarães e Tennis (2013) que o definiram todo o conhecimento produzido por uma pessoa ou instituição e reunido em um fundo de arquivo. Ainda segundo os autores, é possível enxergar o trabalho descritivo da Arquivística como uma forma de organização do conhecimento (OC), uma vez que em sentido estrito, a OC pode ser definida enquanto "atividades de descrição, indexação e classificação de documentos realizadas em bibliotecas, bases de dados e arquivos" (Hjørland 2008, p. 88, tradução livre, grifo nosso).

Os estudos de Guimarães e Tognoli (2015) propiciaram, ainda, a inserção do termo no âmbito do universo científico da International Society for Knowledge Organization - ISKO, iniciando um desdobramento do universo teórico e metodológico da Arquivística, inserindo seus processos em um contexto mais amplo de discussão, como o da análise de domínio, por exemplo. Segundo os autores, "os estudos sobre a proveniência configuram-se em uma abordagem de análise de domínio específica, indo muito além de apenas uma estrutura para análise de domínio na organização do conhecimento arquivístico" (Guimarães; Tognoli, 2015, p. 568).

Sousa (2014), numa reflexão acerca do uso do conceito de classificação na Arquivística, defende a função como um meio para representar a atividade intelectual de construção de instrumentos para organização dos documentos, independentemente da idade à qual eles pertençam.

Ainda, segundo Sousa (2006), essa atividade intelectual permite que o arquivista construa uma representação ideológica, revelando o sentido e o conteúdo das relações entre o sujeito produtor, os documentos, suas funções e as estruturas administrativas às quais estão ligados.

A representação ideológica desse conjunto de fatores resulta em um plano de classificação, que, ao mesmo tempo que relaciona o produtor, os documentos, as funções e as estruturas, também os representa e organiza em classes necessárias ao processo de organização do conhecimento arquivístico.

Às atividades de classificação seguem-se aquelas relacionadas à representação e criação de substitutos para os documentos e seus contextos. Esses substitutos são os chamados instrumentos de pesquisa (guias, inventários, catálogos) que, desde a década de 1990, contam com normas nacionais e internacionais para a padronização de descrições multiníveis, garantindo, assim, uma representação padronizada e passível de interoperabilidade.

Assim como a classificação, a conexão entre o documento e seu contexto - descrição arquivística - é um processo intelectual que também é materializado por meio dos instrumentos de pesquisa resultados dos processos de representação do conhecimento arquivístico e entendidos como uma ponte entre o usuário e o documento. (Tognoli, 2012, p.89).

Podemos dizer que as funções de classificar e descrever possuem um duplo objetivo: organizar e representar o 
conhecimento arquivístico e, por isso, ambas são consideradas processos integrados e complementares.

Esses processos de organização e representação são, portanto, muito mais amplos e complexos do que se fazem parecer, "especialmente quando se refletem além da visão unilateral dos produtos do processo no caso, planos de classificação e instrumentos de pesquisa" (Rodrigues; Barros, 2016, p. 515).

Por conta desta complexidade que vai além de simples geradores de produtos, nas funções de classificação e descrição, consideradas no processo de organização e representação desse conhecimento, incidem valores éticos que devem ser respeitados e conhecidos pelos profissionais arquivistas. Esses valores estão presentes nos códigos de ética dos profissionais que, segundo Dingwall (2004, p. 29) servem para fortalecer a confiança entre o profissional e o público, em que o profissional detém o conhecimento necessário para realizar seu trabalho, um "conhecimento diferenciado [que] cria uma assimétrica relação de poder entre o profissional e o cliente". Ainda segundo o autor, os códigos de ética apresentam múltiplos propósitos tais como: aprimorar o status de uma profissão, regulamentar práticas profissionais, definir e delimitar responsabilidades e guiar as ações profissionais.

Pensar a relação entre o arquivista e seu usuário, não é algo tão simples, pois não constitui uma relação bilateral, mas multilateral. Dingwall (2004) formula essas relações na ideia de um triângulo em que, de um lado, têm-se os produtores dos documentos e as pessoas ligadas aos documentos, de outro lado, os usuários dos documentos e, por fim, o arquivista, que tem a função de "mediar a relação entre produtores e usuários que ocorrem indiretamente por meio dos documentos" (Dingwall, 2004, p. 21, tradução livre).

Essa construção da ética arquivística a partir das relações entre produtores de documentos, grupos de usuários e instituições arquivísticas não ocorre de forma contínua, pois, como o autor exemplifica, os "documentos podem ter sido criados há centenas de anos, mas seus produtores continuam tendo necessidades que devem ser atendidas. Da mesma forma, potenciais usuários desses documentos podem ainda nem ter nascido, mas as necessidades desses usuários devem ser levadas em conta" (Dingwall, 2004, p. 29, tradução livre).

No entanto, é necessário que o arquivista tenha ciência de seu poder e influência na organização e na representação dessa relação tão complexa entre produtor, documento e usuário para, a partir disso pensar sobre os valores morais que estão sendo refletidos nessas atividades, que muitas vezes estão repletos de bias, como demonstram Milani $(2010,2014)$ e Pinho (2006, 2010) em seus estudos sobre ética na representação do conhecimento.

\section{Metodologia}

Considerando que o objetivo deste trabalho é discutir a ética e os valores relacionados às funções de classificação e descrição, buscamos identificar nos códigos de ética do profissional arquivista os valores inerentes a essas funções.

Para tanto, os procedimentos metodológicos foram realizados na busca e análise dos códigos de conduta do profissional arquivista, a partir da análise de conteúdo proposta por Bardin (2009), entendida como "[...] um conjunto de técnicas de análise das comunicações" (Bardin, 2009, p. 31).

O corpus da pesquisa constitui-se em 16 códigos de ética, compreendendo 10 países e 1 instituição Internacional (International Council of Archives -ICA), a saber:

AUSTRÁLIA - Code of Ethics. Australian Society for Archivists (ASA);

BRASIL - Princípios Éticos. Associação dos Arquivistas Brasileiros (AAB);

CANADÁ - Code de déontologie. Association des archivistes du Québec (AAQ); Code of Conduct: Values and Ethics. Library and Archives Canada (LAC). Code of Ethics. Association of Canadian Archivists (ACA1).

ESPANHA - Código deontológico de los archiveros catalanes. Associaó d' Arxivers de Catalunya.;

ESTADOS UNIDOS - Core Values Statement and Code of Ethics. Society of American Archivists (SAA). Role Delineation Statement. Academy of Certified Archivists (ACA2).

FRANÇA - Code de déontologie. Association des Archivistes Français (AAF).

ICA - Code of Ethics. International Council on Archives (ICA).

NOVA ZELÂNDIA - Code of Ethics for the archives $\&$ records association of NZ. Archives and Records Association of New Zealand (ARANZ).

PORTUGAL - Código de Ética. Associação Portuguesa de Bibliotecários, Arquivistas e Documentalistas (APBAD).

REINO UNIDO - A code of Practice on Archives for Museums and Galleries in the United Kingdom. Standing Conference on Archives and Museums (SCAM). Code of Conduct. Archives and Records Association (ARA). Lord Chancellor's code of practice on the management of records under section 46 of the freedom of information act 2000. Ministry of Justice.

SUÍÇA - Code of Ethicis for archivists. Association des Archivistes Suisses (AAS). 
Estabelecemos como categoria de análise, os processos de classificação e descrição e suas equivalências em espanhol, francês e inglês, e como variáveis de inferência estabelecemos a presença/ausência do termo no documento e o valor ético relacionado ao termo.

Sendo assim, tem-se: a) Categoria classificação - variáveis: presença/ausência do termo no código e o valor ético e b) Categoria descrição - variáveis: presença/ausência do termo no código e o valor ético.

Ambas categorias foram aplicadas aos códigos de condutas como se verifica nos resultados apresentados e discutidos a seguir.

\section{Apresentação, análise e discussão dos dados}

Conforme descrito na metodologia, teve-se, como categorias, os processos de classificação e descrição e suas equivalências em espanhol, francês e inglês, e como variáveis de inferência foi estabelecido a presença/ausência do termo no documento e o valor ético relacionado ao termo.

Nos resultados da primeira variável de inferência, dos 16 documentos selecionados, os termos procurados estão ausentes em seis documentos, sendo eles: Brasil AAB, Canadá - AAQ, Canadá - LAC, Estados Unidos - SAA, Nova Zelândia - ARANAZ e Portugal APBAD, o que diminuiu o corpus de análise para dez documentos, nos quais os termos estão presentes.

Nesse conjunto, dos dez documentos analisados, seis apresentaram em seu conteúdo os dois termos (classificação e descrição), enquanto três apresentaram somente o termo classificação, e apenas um documento apresentou somente o termo descrição. ${ }^{2}$

$\mathrm{Na}$ categoria "classificação" os valores encontrados foram: acesso à informação; respeito à proveniência; respeito à ordem original; preservação do valor arquivístico do documento; preservação; conservação; confiabilidade; autenticidade; custódia; e imparcialidade.

Na categoria "descrição" os valores encontrados foram: acesso à informação; respeito à proveniência; respeito à ordem original; preservação; confiabilidade; custódia; e imparcialidade.

Nesse sentido, onze valores foram encontrados voltados a organização e representação do conhecimento arquivístico.

O valor de acesso à informação é o que mais se repete, ou seja, possibilitar o acesso à informação nos arquivos é um dos valores mais destacados pelos documentos de conduta profissional do arquivista. Esse dado confirma as questões anteriormente tratadas por Guimarães et al (2008) no âmbito da Biblioteconomia, em que o acesso à informação é, antes, encarado como um supra valor.

Em seguida, tem-se o respeito à proveniência e o respeito à ordem original. Tais princípios são essenciais, pois a partir deles se delimitam os fundos documentais e sua organização iniciando, assim, um dos primeiros passos para a organização arquivística, para que o profissional possa realizar as atividades de classificação e descrição. É significativa tal incidência, uma vez que tais princípios constituem a espinha dorsal da Arquivística como campo de estudo.

Para demonstrar a importância desses três valores, retoma-se o caso relatado por Eriksen (2010) na seção 02, em que o valor de acesso à informação é crucial em relação à ética arquivística e às atividades de classificação (tanto no sentido de organização, como no sentido de classificar a informação, como vemos na LAI brasileira) e descrição, pois trazem à tona alguns questionamentos como: quem se responsabiliza pelo profissional que não realiza o seu trabalho de forma correta $\mathrm{e}$ adequada perante a sociedade e a seus pares, ou quando a instituição a qual esse profissional está ligado, não cumpre seu dever em dar acesso à informação conforme o que é previsto na lei? Num caso como esse relatado, como ter a certeza de que o respeito à proveniência e à ordem original, fundamentados na teoria Arquivística como essenciais para o desenrolar de qualquer atividade dentro de um arquivo, estão sendo aplicados?

Pensando os valores de respeito à proveniência e respeito à ordem original, pode-se mais uma ver verificar a importância deles nas atividades de classificação e descrição, como demonstra Zhang (2012) em seu estudo ao tratar sobre a ética na representação arquivística de documentos digitais. O princípio da proveniência, por exemplo, "fornece uma representação mais abrangente dos documentos de arquivo oriundos de uma determinada instituição e aborda as questões de quem, onde, quando, como, porquê e quais - se relacionam com esses documentos", e ainda "ajuda a colocar o documento em um contexto de modo que o seu conteúdo se torne compreensível, sua interpretação precisa, e sua relação significativa" (Zhang, 2012, p. 333-334, tradução livre).

Quanto ao valor do respeito à ordem original, a autora salienta que os documentos não devem apenas ser mantidos juntos, mas também "devem ser mantidos do mesmo jeito que foi organizado para seus propósitos de criação" o que garante que "todas as estruturas organizacionais significativas impostas pelos produtores de documentos não devem ser modificadas após os documentos serem transferidos para os arquivos" (Zhang, 2012, p. 334, tradução livre).

Sendo assim, pode-se entender que tais valores estão fundamentados tanto na teoria Arquivística, quanto na prática da área, e quando o profissional opta por não dar atenção a esses valores, outros valores consequentemente são afetados, como o de acesso à informação, observado nos casos apresentados por Eriksen (2010).

Sequencialmente, tem-se os valores relacionado à preservação e conservação do documento, que estão dire- 
tamente ligados ao suporte em que a informação foi registrada; $\mathrm{O}$ valor de preservação está ligado à "função arquivística destinada a assegurar as atividades de acondicionamento, armazenamento, conservação e restauração de documentos", (Camargo, Bellotto, 1996, p. 61), já o de conservação está voltado ao "conjunto de procedimentos e medidas destinadas a assegurar a proteção física dos arquivos contra agentes de deterioração" (Camargo, Bellotto, 1996, p. 18).

Outro valor encontrado refere-se à preservação do valor arquivístico do documento, ou seja, de seus valores probatório e informativo. Para Lopes (1996) o valor de preservação do valor arquivístico do documento evoca primeiramente o que é considerado um documento arquivístico, ou seja, documentos produzidos e/ou recebidos por pessoa física ou jurídica que comprove uma atividade. O valor probatório "depende do caráter e da importância da matéria provada, isto é, da origem e dos programas substantivos, ou fim, da entidade que produziu os documentos", e o valor informativo, "são inerentes aos documentos devido à informação que contêm" (Shellenberg, 2006, p. 183). As atividades de classificação e descrição contribuem para a manutenção desse valor na medida em que reflete em seu plano de classificação e em seus instrumentos de acesso e pesquisa aos documentos, o valor probatório e informativo, evidenciando o contexto de produção desse documento.

$\mathrm{O}$ valor de confiabilidade pode ser entendido como o "grau de fidelidade de uma informação em relação à origem" (Cunha, Cavalcanti, 2008, p. 100), podendo ser refletido em um plano de classificação. Já o valor de custódia está relacionado à "responsabilidade jurídica, temporária ou definitiva, de guarda e proteção de documentos dos quais não se detém a propriedade" (Camargo, Bellotto, 1996, p. 21), podendo ser evidenciado por meio da descrição arquivística.

O valor de imparcialidade, ou de neutralidade do arquivista frente aos arquivos (instituição e/ou documentos), é algo que vem sendo tratado tanto na teoria como em códigos de ética em âmbito nacional e internacional (Gilliland, 2011), como pode ser observado no estudo realizado por Rego et al (2014), que ao analisarem os códigos de ética da AAB, CIA e SAA, verificaram que todos apresentaram o valor relacionado à imparcialidade. Para alguns autores da área (Delmas, 2010; Bellotto, 2014), a imparcialidade é um valor que guia o seu fazer profissional, desde o tratamento documental ao atendimento ao usuário. No entanto, o estudo de Gilliland (2011) apresenta alguns questionamentos em relação a esse valor, pois em um primeiro momento a "neutralidade" é "comumente definida pela sociedade como imparcial, tolerante, sem ideologia, e objetividade" (p.196). Porém, há outras características que também são associadas a esse termo, como "desprendimento, desinteresse, não engajamento, não envolvimento, não participação e não intervenção" (p.207).
Tem-se então o que chamamos de "dois lados da mesma moeda", em que a autora questiona: "Pode de fato a neutralidade sempre apoiar os interesses de todas as partes de um documento de forma igual ou até mesmo equitativa?" (Gilliland, 2011, p. 207, tradução livre).

Ainda sobre esse valor, observa-se que processos de classificação e descrição não são imbuídos de imparcialidade, pois quando o arquivista escolhe trabalhar com um plano de classificação funcional, logo estará excluindo o modo estrutural, ou na descrição, quando o profissional escolhe descrever somente o fundo documental e resolve não descrever os itens documentais, está escolhendo a forma e qual tipo de informações irá disponibilizar ao seu usuário. Dessa maneira, o valor da imparcialidade não cabe ao arquivista, pois estará enganando a si mesmo e ao seu usuário.

Quanto ao valor de autenticidade, têm-se que a autenticidade é a qualidade de um documento quando este preenche as formalidades necessárias para que se reconheça sua proveniência, independentemente da veracidade do respectivo conteúdo (Camargo, Bellotto, 1996, p. 10). Esse valor compreende, ainda, duas características identificadas como "identidade" e "integridade". A primeira está ligada aos elementos do documento que o caracterizam e o distinguem dos demais. Tais elementos são descritos por Duranti (2002) como as pessoas que participam da formação do documento, datas de criação e transmissão, atividade da qual participa e o vínculo arquivístico. Para a autora a integridade referese à completude do documento, se ele está intacto e não foi adulterado. Neste sentido, Duranti entende que um documento é íntegro se sua mensagem não foi alterada.

As funções de classificação e descrição ao lançar luz sobre os procedimentos administrativos de criação dos documentos de arquivo, estabelecem as relações hierárquicas e contextuais dos documentos com suas funções e atividades, construindo planos de classificação e instrumentos de pesquisa, organizando e representando todos os elementos que caracterizam o documento enquanto autêntico. O valor da autenticidade, portanto, está intrinsicamente ligado às funções de organização e representação, indo além do conteúdo informacional do documento.

O valor de segurança da informação é constituído por "procedimentos para proteção do acervo informacional de uma organização contra o acesso ou uso por pessoas não-autorizadas", caracterizados pela preservação de alguns aspectos como a) confiabilidade: garantia de que a informação é acessível somente por pessoas autorizadas; b) integridade: salvaguarda da exatidão e completeza da informação e dos métodos de processamento; c) disponibilidade: garantia de que os usuários autorizados obtenham acesso à informação (Cunha; Cavalcanti, 2008, p. 329). Esse valor está diretamente ligado àquele de acesso à informação, e à função de descri- 
ção, na medida que um dos objetivos finais dessa atividade é garantir o acesso à informação pelo usuário.

\section{Conclusões}

Classificação e descrição são consideradas funções nucleares na organização e representação do conhecimento no âmbito dos arquivos justamente porque são responsáveis por refletir não apenas os produtos de seus respectivos processos, mas por representarem pontos de intersecção entre as demais ações relacionadas aos documentos arquivísticos, revelando um universo axiológico rico e diversificado, o que testemunha a natureza eminentemente social da Arquivística e o seu compromisso com o patrimônio documental da humanidade de modo a garantir-lhe "permanência no tempo e portabilidade no espaço" (Smit e Barreto 2002, p.21).

Desse modo, torna-se imprescindível refletir sobre a ética e os valores relacionados a essas funções, pois elas são realizadas por um profissional que irá decidir sobre "como, por que, para que, para quem" esses documentos estão sendo classificados e descritos, e em quais valores deve-se basear para tanto. Enfim, tem-se, aqui, a reiteração daquilo que Hope Olson (2002) denominou como o "poder de nomear".

Por fim concluímos que novas e instigantes perspectivas se abrem, no âmbito da pesquisa dos aspectos éticos que integram esse novo campo de estudos - a organização do conhecimento arquivístico - que, nos últimos anos, vem ganhando significativo espaço no âmbito da International Society for Knowledge Organization - ISKO.

\section{Notes}

(1) Não fazemos aqui a distinção de Schellenberg (2006) entre records managements e archivists, pois entedemos $\mathrm{o}$ arquivista atuando desde a produção documental.

(2) Documentos com os dois termos: Austrália - ASA, Canadá - ACA1, Estados Unidos - ACA2, Reino Unido ARA, Ministery of Justice, Suíça - AAS. Documentos somente com o termo classificação: França - AAF, ICA, Reino Unido - SCAM. Documento somente com o termo descrição: Espanha: - Associaó d' Arxivers de Catalunya

\section{References}

AAB. Associação dos Arquivistas Brasileiros. (2014). Princípios Éticos.

http://web.archive.org/web/20131030071756/http://www.aab.org .br/?page_id=27. (2014-06-29)

AAF. Association dês Archivistes Français. (2014). Code de déontologie. http://www.archivistes.org/Code-de-deontologie (201406-29).

AAQ. Association des archivistes du Québec. (2014). Code de déontologie. http://www.archivistes.qc.ca/a-propos/code-dedeontologie (2014-06-29).
AAS. Association des archivistes suisses. (2014). Code of Ethicis for archivists. http://www.vsa-aas.org/fr/beruf/code-of-ethics/. (2014-06-29).

Abela, A.V. (2008) Digesting the Raisins of Wrath: Business, Ethics, and the Archival Profession// The American Archivists.71 (spring/summer): 203-209, 2008.

ACA. (1) Association of Canadian Archivists. Code of Ethics. (2014) http://archivists.ca/content/code-ethics.

ACA. (2) Academy of Certified Archivists. (2014) Role Delineation Statement.

http://www.certifiedarchivists.org//?s=The+2003+Role+Delineat ion+Statement+Revision.

APBAD. Associação Portuguesa de Bibliotecários, Arquivistas e Documentalistas. (2014) Código de ética. Disponível em: $<$ http://www.apbad.pt/Downloads/codigo_etica.pdf >. (2014-0629)

ARA. Archives \& Records Association. Code of Conduct. (2014) $<$ http://www.archives.org.uk/images/documents/ARACouncil/A RA_Code_of_Conduct_final.pdf>. (2014-06-29)

ARANZ. Archives and Records Association of New Zealand. (2014) CODE OF ETHICS FOR THE ARCHIVES \& RECORDS ASSOCIATION OF NZ. http://www.aranz.org.nz/Site/about_ARANZ/code_of_ethics.asp $\mathrm{x}>$. (2014-06-29)

ASA. Australian Society of Archivists. (2014) Code of Ethics. Disponível

em:<http://www.archivists.org.au/page/About/Code_of_Ethics (2014-06-29)

Associació D'arxivers de Catalunya. (2014) Código deontológico de los archiveros catalanes. http://www.arxivers.com/index.php/documents/publicacions/colleccio-textos-1/textos-traduccions-1/130-textos-01-codigodeontologico-de-los-archiveros-catalanes-1/file>. (2014-06-29)

Bardin, L. (2009). Análise de Conteúdo. Lisboa, Portugal: Edições 70, LDA, 2009.

Barros, T. H. B. (2015). Uma trajetória da Arquivística a partir da Análise do Discurso [recurso eletrônico]: inflexões históricoconceituais. São Paulo: Cultura Acadêmica, 2015.

Bellotto, H.L. (2014). Qualificação profissional e o código de ética do arquivista// Arquivo, estudos e reflexões. Belo Horizonte: Editora UFMG (2014) 268-277.

Borko, H. (1968). Information Science: What is it? //American Documentation. 19:1 (1968) 3-5.1968.

Bufrem, L.S; Breda, S.M.; Sorribas, T.V.; Freitas, J. L. (2008). Ética e formação profissional: uma leitura da produção científica em Ciência da Informação (1970-2006) //TransInformação. 20:3 (2008) 225-232.

Camargo, A.M.de A.; Bellotto, H.L. (1996) (Org.) Dicionário de terminologia arquivística. São Paulo: Associação dos Arquivistas Brasileiros - Núcleo Regional de São Paulo: Secretaria do Estado da Cultura, 1996.

Cook, M. (2006) Professional Ethics and Practice in Archives and Records Management in a Human Rights Context // Journal of the Society of Archivists. 27:1 (2006) 01-15. 2006.

Cook, T. (1997) "What is Past is Prologue: A History of Archival Ideas since 1898, and the Future Paradigm Shift" // Archivaria 43 Spring (1997) 20-22.

Cortina, A. Martinez, E. (2005). Ética. São Paulo: Edições Loyola, 2005.

Couture, C. (2010). Les fonctions de l'Archivistique contemporaine. Québec: Presses de l'Université du Québec, 2010.

Cox, D. (2013). In the trenches. Archival Ethics, Law and the Case of the Destroyed CIA Tapes. // Journal of Information Ethics. 22: 02 (2013) 90-101. 
Cox, R.J. (2010) Teaching, Researching, and Preaching Archival Ethics Or, How These New Views Came to Be. // Journal of Information Ethics. 19:01 (2010) 20-32.

Cunha, M.B. da.; Cavalcanti, C.R.de O. (2008) Dicionário de Biblioteconomia e Arquivologia. Brasília - DF: Briquet de Lemos / Livros, 2008.

Danielson, E.S. (2010). The Ethical Archivist. United States of America: Society of American Archivists, 2010.

Danielson, E.S. (2013). Archives and the Ethics of Replevin. //Journal of Information Ethics. 22:02 (2013) 110-136

Delmas, B. (2010). Arquivos Para Quê? São Paulo: Instituto Fernando Henrique Cardoso (IFHC), 2010

Dingwall, G. (2004). Trusting Archivists: The Role of Archival Ethics Codes in Establishing Public Faith. // The American Archivist. 67 (spring/summer) (2004) 11-30.

Duchein, M. (1983). Theorical principles and practical of respect dês fonds in Archival Science. // Archivaria, 16:sumer (1983) 64-82.

Duranti, L. (2002). Authenticity and Appraisal: Appraisal Theory Confronted With Electronic Records. // Proceedings of the 3rd International Colloquium on Library and Information Science: "The Refined Art of the Destruction: Records' Appraisal and Disposal,": University of Salamanca, October 9-11, 2002. Salamanca, 2002.

Eriksen, K. (2010). The Archival Profession's Failure to Respond to the National Archives' Breaches of Professional and Ethical Duties. // Journal of Information Ethics. 19:01 (2010) 157-171.

Fernández-Molina, J. C; Guimarães, J. A. C. (2002). Ethical aspects of knowledge organization and representation in the digital environment: their articulation in professional codes of ethics. In: LÓPEZHUERTAS, M. J. (Ed.). // Challenges in knowledge representation and organization for the 21st century: integration of knowledgeacross boundaries. Würzburg: ERGON-Verlag, 2002.

Gilliland, A. (2011). Neutrality, social justice and the obligations of archival education and educators in the twenty-first century. // Archival Science, 11(2011) 193-209.

Guimarães, J.A.C; Tognoli, N.B. (2015). Provenance as a Domain Analysis Approach in Archival Knowledge Organization // Knowledge Organization 42: 8 (2015) 562-569

Guimarães, J.A.C. (2006). Aspectos éticos em organização e representação do conhecimento: uma reflexão preliminar. (Org.) GÓMEZ, M.N.G. de; ORRICO, E.G.D. // Políticas de memória e informação: reflexos na organização do conhecimento. Natal $[\mathrm{RN}]$ : EDUFRN, 2006

Guimarães, J.A.C.; Fernandez-Molina, J. C. (2010) Ética en organización y representación del conocimiento: aspectos teóricos. Nuovi Annali della Scuola Speciale per Archivisti e Bibliotecari, v. XXIV , (2010) 235-251.

Guimarães, J.A.C.; Milani, S. de O.; Pinho, F. (2008) A. Aspectos éticos em organização e representação do conhecimento: uma análise preliminar de valores e problemas a partir da literatura internacional da área. // Encontros Bibli (UFSC), 13 (2008) 124135 .

Hjørland, B. (2008). What is Knowledge Organization (KO)? //Knowledge Organization. 35:2 (2008) 86-102.

ICA. International Council on Archives. Code of Ethics. Disponível em:< http://www.ica.org/?lid=5555\&bid=225>. (2014-06-29).

ICA. International Council on Archives. (2010). DECLARAÇÃO UNIVERSAL SOBRE OS ARQUIVOS. 2010. <http://www.ica.org/?lid=13343\&bid=1101>. (2016-03-08)

Japiassu, H; Marcondes, D. (2008) Dicionário básico de filosofia. 5.ed. Rio de Janeiro: Jorge Zahar, 2008

LAC. Library and Archives Canada. (2014) Code of Conduct: Values and Ethics. http://www.bac-lac.gc.ca/eng/about-us/Pages/codeconduct-value-ethics.aspx>. (2014-06-29).

Lopes, L. C. (1996). A informação e os arquivos. Teorias e práticas. Niterói: EDUFF; São Carlos: EDUFSCar, 1996.
Mason, R.O (1990). What is an information professional? // Journal of Education for Library and Information Science. 31:2 (1990) 122-138

Milani, S. O. (2010). Estudos éticos em representação do conhecimento: uma análise da questão feminina em linguagens documentais brasileiras. 2010. 141 f. Dissertação (Mestrado em Ciência da Informação) - Faculdade de Filosofia e Ciências, Universidade Estadual Paulista, Marília, 2010.

Milani, S.O. (2014). Bias na Representação de Assunto: Uma Discussão de Oposições Binárias nos Functional Requirements for Subject Authority Data (FRSAD), 2014. 134f. Tese (Doutorado em Ciência da Informação) - Faculdade de Filosofia e Ciências, Universidade Estadual Paulista, Marília, 2014.

Ministry of Justice. (2014) Lord Chancellor's code of practice on the management of records under section 46 of the freedom of information act 2000 http://www.justice.gov.uk/downloads/information-accessrights/foi/foi-section-46-code-of-practice.pdf > . (2014-06-29)

Mitchell, W.B. (2013). A Nonte on Civil Disobedience and Professional Ethics Codes. //Journal of Information Ethics, 22:02 (2013) 61-65.

Olson, H. (2002) Naming is Power. In: The Power to Name. Locating the limits of Subject Representation in Libraries. Dordrecht: Kluwer Academic Publisher, 2002.

Pinho, F. A. (2006). Aspectos éticos em representação do conhecimento: em busca do diálogo (Mestrado em Ciência da Informação) - Faculdade de Filosofia e Ciências, Universidade Estadual Paulista, Marília, 2006.

Pinho, F.A. (2010). Aspectos éticos em representação do conhecimento em temáticas relativas à homossexualidade masculina: uma análise da precisão em linguagens de indexação brasileiras, 2010. 149 f. Tese (Doutorado em Ciência da Informação) - Faculdade de Filosofia e Ciências, Universidade Estadual Paulista, Marília, 2010.

Rego, L.M. Silva, A.P. da; Martínez-Avila, D. Tognoli, N.B. (2014) Aspectos éticos na organização do conhecimento na prática profissional arquivística: um estudo dos princípios de étca da $\mathrm{AAB}$, CIA e SAA. // Scire, 20:2 (2014) 37-42.

Rodrigues, W.M.; Barros, T.H.B (2016). Representação e descrição arquivística: um estudo do ementário dos cursos de Arquivologia do Brasil //Revista Analisando em Ciência da Informação RACIn. 4: especial (20016) 510-525.

Rousseau, J.Y; Couture, C. (1998). Os fundamentos da disciplina arquivística. Lisboa: Dom Quixote, 1998

Sá, A.L. de. (2000) Ética Profissional. 3.ed. São Paulo: Atlas, 2000.

SAA. Society of American Archivists. Core Values Statement and Code of Ethics. (2012) http://www2.archivists.org/statements/saa-core-valuesstatement-and-code-of-ethics\#core_values. (2014-06-29).

SCAM. Standing Conference on Archives and Museums. (2002) A code of Practice on Archives for Museums and Galleries in the United Kingdom. http://www.archivesandmuseums.org.uk/scam/code.pdf. (201406-29).

Schellenberg, T.R. (2006). Arquivos modernos: princípios e técnicas. 6 ed. Rio de Janeiro: FGV, 2006.

Silva, A. P. da. (2016). Aspectos éticos em organização da informação: Um estudo em códigos de ética do profissional arquivista. Dissertação (Mestrado) - Programa de Pós-Graduação em Ciência da Informação - Faculdade de Filosofia e Ciências, Universidade Estadual Paulista - UNESP, Marília, 2016.

Silva, A.P. da; Guimarães, J. A. C.; Tognoli, N. B. (2015). Ethical Values in Archival Arrangement and Description: An Analysis of Professional Codes of Ethics. Knowledge Organization, 42:5 (2015) 346-352

Smit, J.W; Barreto, A. de A. (2002). Ciência da informação: base conceitual para a formação do profissional. // VALENTIM, 
M.L.P. (org.) Formação do profissional da informação. São Paulo: Polis, (2002) 9-23.

Sousa, R.T.B (2014). Alguns apontamentos sobre a classificação de documentos de arquivo // Brazilian Journal of Information Science: new research trends. 8:1/2 (2014) 1-24.

Sousa, R.T.B. (2006). Classificação de documentos arquivísticos: trajetória de um conceito// Arquivística.net. 2:2 (2006) 120-142.

Souza, F. das C. de. (2002). Ética e deontologia: textos para profissionais atuantes em bibliotecas. Florianópolis: Ed UFSC, 2002.

Thomassem, T. (2006). Uma primeira introdução à arquivologia. // Arquivo\&administração, 5:1 (2006) 5-16.

Tognoli, N.B.; Guimarães, J.A.C.; Tennis, J.T. (2013) Diplomatics as a methodological perspective for archival knowledge organization. // 4th North American Symposium on Knowledge Organization (NASKO) Transition Cultures, Transition KO: Evolving Exploration, Critical Reflection, and Practical Work. Milwaukee, 2013.
Wallace, D.A. (2010). Interdisciplinary Perspectives on Professional Ethics and Archival Morality. // Journal of Information Ethics. 19:01 (2010) 172-189.

Zhang, J. (2012). Archival Context, Digital Content, and the Ethics of Digital Archival Representation. // Knowledge Organization, 39:05 (2012) 332-339.

Copyright: (0 2017. Silva et al. This is an open-access article distributed under the terms of the Creative Commons CC Attribution-ShareAlike (CC BY-SA), which permits use, distribution, and reproduction in any medium, under the identical terms, and provided the original author and source are credited.

Received: 2017-01-27 Accepted: 2017-01-27 